\title{
TLRs, Treg, and B cells, an interplay of regulation during helminth infection
}

\author{
Isis Ludwig-Portugall ${ }^{1}$ and Laura E. Layland ${ }^{2,3} *$ \\ 1 Institutes of Molecular Medicine and Experimental Immunology, University Bonn, Bonn, Germany \\ 2 Institute of Medical Microbiology, Immunology, and Parasitology, University Clinic Bonn, Bonn, Germany \\ ${ }^{3}$ Institute of Medical Microbiology, Immunology and Hygiene, Technische Universität München, Munich, Germany
}

Edited by:

Anthony L. DeFranco, University of California, USA

\section{Reviewed by:}

Masaki Hikida, Kyoto University, Japan

Liwei Lu, The University of Hong Kong, Hong Kong

\section{*Correspondence:}

Laura E. Layland, Institute of Medical Microbiology, Immunology and Hygiene, Technische Universität München, Trogerstrasse 30, 81675 Munich, Germany.

e-mail: laura.layland@mikrobio.med. tum.de
Commonly described as masters of regulation parasitic helminth infections provide a fascinating insight into the complexity of our immune system. As with many other pathogens helminths have developed complex evasion strategies and the immune response of the host has to find a balance between eliciting severe damage to eliminate the parasite or limiting damage and thereby accepting the infection. Nevertheless, one should not forget that these infections still pose a serious public health problem and can elicit severe disfigurement or death in the individual. An interesting spin-off of helminth manipulation on host responses is the apparent prevention of autoimmune diseases or allergy although the actual mechanisms remain unclear. It is well known that Toll-like-receptors (TLR) and non-TLR PRRs play a critical role in initiating innate immune responses which in turn create appropriate adaptive immune reactions. Helminths comprise of a multitude of (glyco)-proteins and (glyco)-lipids and some have been shown to trigger TLR, or alter TLR-mediated responses. Such reactions of course alter adaptive immunity as well. This review will address the consequences of TLR-triggering by helminth antigens and the downstream effect on B cell and regulatory $T$ cell (Treg) actions.

Keywords: helminth, B cells, regulatory T cells, TLR, immune-regulation

\section{IMMUNE RESPONSE TO HELMINTHS}

In contrast to micro-parasites which evade host detection by antigenic variation or elaborate subterfuge, helminths are elaborately bold and have flourished in mammalian hosts throughout our evolution. Although a diverse range of nematodes (roundworms), trematodes (flatworms), and cestodes (tapeworms) have adopted humans as their definite hosts and dwell in various organs and lymphatics, the invoked immune responses by the host are surprisingly stereotypical (Maizels and Yazdanbakhsh, 2003; Maizels et al., 2004; Anthony et al., 2007). These culminate in the production of various Th2 associated cytokines (IL-5, IL-13, IL-4) and immunoglobulins (IgE) from effector cells which all stem from a cacophony of cellular responses such as mast cell and eosinophil mobilization. The absolute requirement for type 2 immunity has been demonstrated in various infection systems but this response rarely results in expulsion of the parasite (Allen and Maizels, 2011). Indeed, although helminths can elicit severe immunopathology, the majority of infections remain asymptomatic, that is, the host tolerates the worm and it is this immuno-modulatory capacity of the worm that currently fascinates many immunologists (Moreau and Chauvin, 2010). The well-documented induction of regulatory T cells (Treg) during various helminth infections (Everts et al., 2010; Grainger et al., 2010; Layland et al., 2010; Blankenhaus et al., 2011) has also provided insight into the evolutionary direction of such hypo-responsive states: coveting the host's self-imposed system of immune homeostasis and self-tolerance. Interestingly, upon cure of infection, expanded populations of Treg return to normal levels and this is usually accompanied by ameliorated responses to foreign antigens (Kamradt, 2005; Layland et al., 2007).

\section{HELMINTH-MEDIATED IMMUNE-MODULATION ON INNATE CELLS}

The requirement of triggering PRR on innate cells, and the consequential necessity of pro-inflammatory responses to pathogenic organisms is an undisputed fact (Medzhitov and Janeway, 1997). In addition, there is now a wealth of literature emphasizing the importance of such stimulations in directing efficient and appropriate adaptive immune reactions (Pasare and Medzhitov, 2005; Schenten and Medzhitov, 2011). Indeed, several studies have demonstrated that ongoing infections in the absence of certain TLR, deviates adaptive responses which exacerbates the immunopathology of the host. This is of particular interest when studying parasitic infections, such as helminths since they utilize such immune-regulation for their own survival (Venugopal et al., 2009; Everts et al., 2010). In this regards, much research has focused on the responses of classical innate cells such as dendritic cells (DC) and macrophages. TLR-triggering of DC promotes pro-inflammatory/Th1 environments which would theoretically coincide with the typically induced Th1 responses observed in the acute phase of helminth infections (Maizels and Yazdanbakhsh, 2003; Maizels et al., 2004, 2009; Anthony et al., 2007; Hotez et al., 2008; Allen and Maizels, 2011). Although such correlations were observed using dsRNA from the eggs of the tropical trematode Schistosoma mansoni which activates TLR3 (Aksoy et al., 
2005), helminth antigens are more renowned for their non-chalant behavior on DC activation; namely their failure to induce conventional pro-inflammatory activation and maturation. For example, soluble egg antigen (SEA), derived from S. mansoni eggs, does not elicit TLR-triggered responses when co-cultured with innate cells per se but actually dampens pro-inflammatory cytokine release elicited upon co-culture with LPS (Kane et al., 2004; van Liempt et al., 2007; Ritter et al., 2010). Many helminth antigen preparations contain a large mixture of proteins, glyco-proteins, and glyco-lipids and whereas some have been shown to modulate various TLR others have been shown to activate other PRR families. For example, the calreticulin protein, isolated from the gastrointestinal nematode Heligmosomoides polygyrus can induce IL-4 production through activation of the class A scavenger receptor (SR-A; Rzepecka et al., 2009). With regards to SEA, a (glyco)protein-based component was found to signal through Dectin-2, a C-type lectin, activating the Nlrp3 inflammasome, and inducing the production of bioactive IL- $1 \beta$. Intriguingly, this process occurred simultaneously to the dampening of TLR-mediated TNF release and was shown to be facilitated by a different component since heat inactivation of SEA destroyed the former but not the latter. The Nlrp3 inflammasome activation was further shown to be independent of phagocytosis but dependent upon ROS, $\mathrm{K}^{+}$ influx and Syk signaling, and in vivo studies using inflammasome deficient strains, infected mice showed skewed Th responses, and reduced granuloma formation (Ritter et al., 2010). Interestingly, several studies have shown the sensing of helminth-derived glycans through this family of carbohydrate binding receptors which include the mannose receptor and DC-SIGN (DC-specific intracellular adhesion molecule-3-grabbing non-integrin). Antigens from Toxocara canis, Brugia malayi, Caenorhabditis elegans, and schistosomes have been associated with DC-SIGN and there is strong evidence that CLR triggering on DC by helminth glycans drives Th2 polarized responses (Okano et al., 1999, 2001; van Die et al., 2003; Tawill et al., 2004; Meyer et al., 2005; Schabussova et al., 2007). Although helminth components fail to induce conventional
DC maturation - leading to impaired Th1 development - all interactions appear to drive Th2 or regulatory responses and some are highlighted in Table 1. Several products have been shown to prime such responses including the phosphorylcholine-containing glycoprotein ES-62 from Acanthocheilonema viteae which triggers TLR4 inducing an anti-inflammatory and Th2 inducing APC phenotype (Whelan et al., 2000; Goodridge et al., 2005, 2007). This nematode is of particular interest since it does not contain the endosymbiont bacteria Wolbachia. This relationship is essential to other filarial worms since its death through antibiotic treatment leads to worm sterility and death (Taylor et al., 2010). The bacteria is also thought to mediate immune responses by triggering TLR2 and 4 (Brattig et al., 2004). Phospholipids from schistosomes and ascaris worms also trigger TLR2 and the lysophosphatidylserine could activate DCs to induce Th2 and IL-10-producing Treg (van der Kleij et al., 2002; van Riet et al., 2009). Since then other infectious systems have noted the triangle of interaction between TLR2-IL-10 and Treg and these aspects are commented upon in the latter part of this review.

\section{ROLE OF B CELLS IN HELMINTH INFECTION AND TLR}

Surprisingly, despite possessing an array of PRR little is known about the effects of helminth-derived products on innate $B$ cell responses. Both TLR2 and TLR4 were found to be expressed on circulating B cells during helminth infection reflecting systemic microbial ligand exposure. It was speculated that this bacterial translocation may be induced by schistosomal egg movement from the vascular system to the gut or the skin during infection (Onguru et al., 2011). Several reports have noted that B cells promote and support Th2 type-immune responses during helminth infections, in order to control opposing Th1-type responses (Hernandez et al., 1997; Moulin et al., 2000; Blackwell and Else, 2001). Their production of IgE represents one the classical hallmarks of helminth diseases and this immunoglobulin can trigger degranulation and the release of soluble factors from mast cells and basophils (Pennock and Grencis, 2006; Voehringer, 2009). Although the role of IgE

Table 1 | An overview of selective helminth-derived products, their innate cell signaling component, and the effects they have on the adaptive immune system.

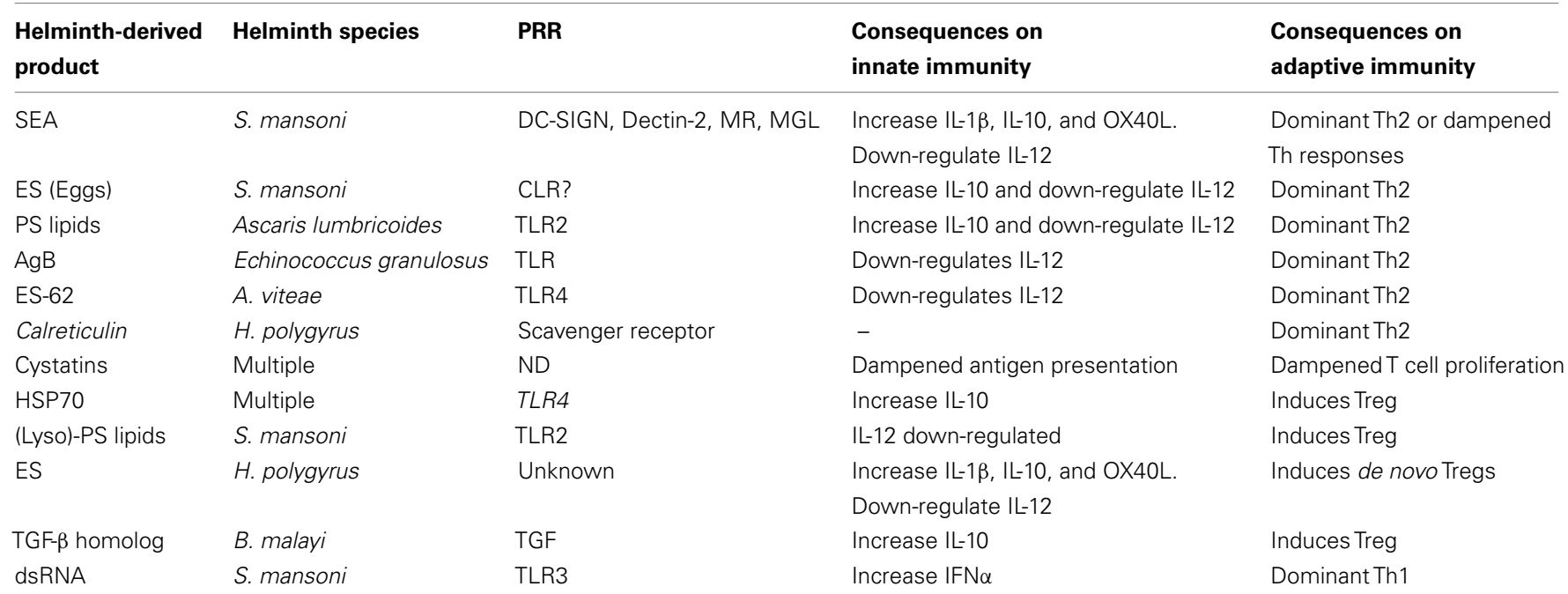


in providing protective immunity appears limited, other antibodies, particularly IgM and IgG, have been shown to be effective. In addition, several helminth models have demonstrated antibodymediated passive immunity and parasite-specific maternal IgG can protect offspring from $H$. polygyrus or Trichinella spiralis (Harris and Gause, 2010). However, a recent study showed that the protective role of B cells seems to be more distinct. Using B cell deficient mice, Liu et al. (2010) demonstrated that most of the parameters of mucosal primary and memory Th2 responses after infection with $N$. brasiliensis or $H$. polygyrus are not impaired if B cells are missing. The only scenario in which B cells were important was the successful expulsion of the parasite $H$. polygyrus after secondary inoculation. Nevertheless, B cells not only function by producing important protective antibodies (Liu et al., 2010) but through antibody-independent activities as well including antigen presentation, providing co-stimulation and regulatory/effector functions (Linton et al., 2003; Harris and Gause, 2010).

The first indication of regulatory B cells came from studies on autoimmune diseases such as experimental autoimmune encephalomyelitis (EAE) and type 1 diabetes and interestingly the onset of these diseases can be dampened by ongoing helminth infections (Fillatreau et al., 2008; Hussaarts et al., 2011). Although their induction correlates to dampened Th1 responses they have also been shown to modulate Th2 responses during helminth infections. In schistosomiasis for example, lack of B cells enhances Th2-driven immunopathology and the up-regulation of FasL expression on B cells correlates with increased apoptosis of activated $\mathrm{CD}^{+} \mathrm{T}$ cells (Lundy and Boros, 2002). Recent studies have identified that $\mathrm{CD} 19^{+} \mathrm{CD} 23^{\text {hi }} \mathrm{B} 2 \mathrm{~B}$ cells, induced during $H$. polygyrus infection, have the capacity to down-modulate allergic airway inflammatory reactions (Wilson et al., 2010). In contrast to the previously described IL-10-producing B cells (Smits et al., 2010), these CD23 ${ }^{+}$B cells suppressed allergic responses in an IL-10 independent manner. A possible explanation for their suppressive capacity is the expression of CD23, which is the low affinity IgE receptor and has been shown to have inhibitory effects on airway inflammation (Haczku et al., 2000). Interestingly, resistance to schistosomiasis in hyperexposed individuals was correlated to circulating $\mathrm{CD}_{23}{ }^{+} \mathrm{B}$ cells expressing the $\mathrm{CD} 23 \mathrm{~b}$ isoform and CXCR5, the homing receptor for lymphoid follicles. Moreover, CD23-bound IgE cross-linking increased surface expression of CXCR5, suggesting that these circulating B cells may play a role in the capture and shuttling of schistosomal antigens directly to splenic follicles (Onguru et al., 2011). Further elucidation of these helminth induced regulatory B cells may identify new strategies to modulate chronic inflammatory diseases or attenuate allergic diseases (Amu et al., 2010; Smits et al., 2010). Of interest, in a study of $S$. mansoni-infected individuals with multiple sclerosis it was observed that expression levels of TLR2 were significantly higher on B cells and moreover, could be significantly up-regulated upon exposure to SEA. Furthermore, SEA increased IL-10 production from anti-CD40-activated B cells which in turn suppressed $\mathrm{T}$ cell responses (Correale and Farez, 2009). In association, SEA was shown to induce IL-10 in DC (Kane et al., 2004) and other studies have shown using non-parasite derived antigens that triggering TLR4 can induce IL-10 secretion in B cell in a Myd88-dependent manner (Yanaba et al., 2009).

\section{MECHANISMS OF Treg INDUCTION VIA TLR-TRIGGERING HELMINTH COMPONENTS}

The essential purpose of naturally occurring Treg (nTreg) and induced Treg (iTreg) are well-characterized: prevention of overt reactions to self-antigens and mediating adaptive responses during infection (Rudensky, 2011). Nevertheless, their phenotypic characteristics and functional mechanisms remain incompletely understood. One could imagine that the numerously reported novel features of Treg are subject to not only the underlying disease but also dependent on their location and interaction with other cell types. Furthermore they show high plasticity and there has been flourish of reports demonstrating their reprogramming capabilities (Hori, 2010). For example, human PBMCs contain $\mathrm{CD}^{+}{ }^{+} \mathrm{Foxp}^{+} \mathrm{CCR}^{+}$cells that can produce IL17 upon TCR stimulation, in vitro however, this process requires the presence of IL-1 $\beta$, IL-2, IL-21, and IL-23 (Voo et al., 2009). Again, the requirement of multiple cytokines highlights that reprogramming or phenotypic alterations only occur under certain scenarios. Another facet that remains incompletely understood is the driving force behind iTreg induction. During helminth infections there is a general expansion of Treg $\left(\mathrm{CD} 4{ }^{+} \mathrm{CD} 25^{\mathrm{hi}} \mathrm{Foxp}^{+}\right)$ but this development remains in a homeostatic relationship to $\mathrm{CD}^{+}{ }^{+} \mathrm{T}$ effector cells (Layland et al., 2007, 2010; Blankenhaus et al., 2011; Othman et al., 2011). It is the failure to expand that causes deviations in the immune responses and usually results in exaggerated immunopathology (Layland et al., 2007; McSorley et al., 2008). Such responses were observed during in vivo infections with $S$. mansoni which elicits chronic inflammation of the liver and intestine in over 200 million people worldwide (Wilson et al., 2007). This blood fluke has a complicated lifecycle and within the definite mammalian host, the parasite undergoes no less than three different life-stages. However, as mentioned above, it is not the adult worms of these infections that trigger destructive immune responses but their offspring. In schistosomiasis, the ensuing immunopathology arises from the abundant eggs that are released from fecund females and which must penetrate the intestine to be excreted with the stool. This is facilitated by the development of granulomas which are mediated by schistosome-specific $\mathrm{CD}^{+} \mathrm{T}$ effector cells (Asahi and Stadecker, 2003; Wilson et al., 2007). S. mansoni infections of TLR2-deficient mice displayed overt pathological symptoms due to the failure of these mice to increase the numbers of Treg during infection. The balance could be restored by the adoptive transfer of helminth-specific Treg in deficient animals (Layland et al., 2007). These in vivo experiments correlated to the previously described studies showing that lipids from S. mansoni eggs specifically triggered TLR 2 to induce IL- $10^{+}$Treg. Although correct activation of TLR and NLR signaling pathways are crucial for directing host defenses the role of TLR in Treg induction remains controversial since TLR agonists can have either direct or indirect effects on Treg (Conroy et al., 2008). For example, TLRtriggered IL-6 production from DC can suppress Treg function (Pasare and Medzhitov, 2005) whereas other studies have shown that combinations of IL-1 and IL-6 can enhance the suppressive capabilities of Treg (Kubo et al., 2004). TLR9 on the other hand was shown to directly aid the conversion of effector cells to Treg but this was dependent on the tissue and TLR-activated 
DC subset (Hall et al., 2008; Mills, 2008; Rutitzky and Stadecker, 2011).

A fascinating aspect of helminth infections is the development of initial Th1 responses which convert over time to Th2 responses. Indeed the failure to develop Th2 responses after egg deposition during schistosomiasis results in exacerbated granuloma inflammation due to more prominent Th1 and Th17 responses and results in substantial damage to the hepatic parenchyma, accelerating morbidity (Rutitzky and Stadecker, 2011). Other alterations to the immune balance have been verified in murine studies of S. mansoni infection using various cellular and cytokine deficient strains. The requirement of Treg was first noted in studies with IL-10 knockout mice since these mice developed such overt granuloma responses that they had accelerated death (Hoffmann et al., 2000; Hesse et al., 2004). In helminth infected individuals both IL-10 and TGF- $\beta$ are up-regulated and although Treg are the main source of these anti-inflammatory mediators their release from B cells and other APC have also been shown to dampen overt responses (Hoffmann et al., 2000; Hesse et al., 2004; Mangan et al., 2004; Perona-Wright et al., 2006; Correale et al., 2008; Mitre et al., 2008). In a recent in vitro study by (Grainger et al., 2010) a helminth product termed excretory-secretory antigen [HES] from $H$. polygyrus and another related nematode was shown to induce de novo Foxp3 expression in splenocytes due to the ligation of HES to the TGF- $\beta$ receptor.
In enhancing the knowledge about Treg, it was observed that during schistosomiasis their absence elicited increased immunopathology and moreover, lack of control over schistosome-specific immune responses (Layland et al., 2007, 2010). In other models such as the murine model of filariasis (Litomosoides sigmodontis) and Strongyloides ratti, removal of Treg can lead to worm death but inhibits the priming of Th2 responses as well (Gillan and Devaney, 2005; Taylor et al., 2007; Korten et al., 2008; Allen and Maizels, 2011; Blankenhaus et al., 2011). Helminth-derived Treg also possess greater suppressive activities and can antigen specifically suppress helminth-specific effector $\mathrm{T}$ cells. Although little remains known about the mechanism employed by these cells, characterization, and gene expression profiles have elucidated that such cells have distinctive markers such as CD103 and Granzyme B (Korten et al., 2008; McSorley et al., 2008; Taylor et al., 2009; Layland et al., 2010). These profiles provide hints as to how these cells orchestrate both molecular and cellular events (Figure 1). Expression levels of CTLA-4 and GITR have been identified on Treg during chronic helminth infections in mouse and human and in vivo studies have investigated how the absence of these molecules influences the functionality of Treg. Absence of GITR in Trichuris muris can reduce worm numbers (D'Elia et al., 2009) for example and in already established infection of L. sigmodontis, removal of Treg only has an effect on the parasitic load when combined with blocking CTLA-4 or activating

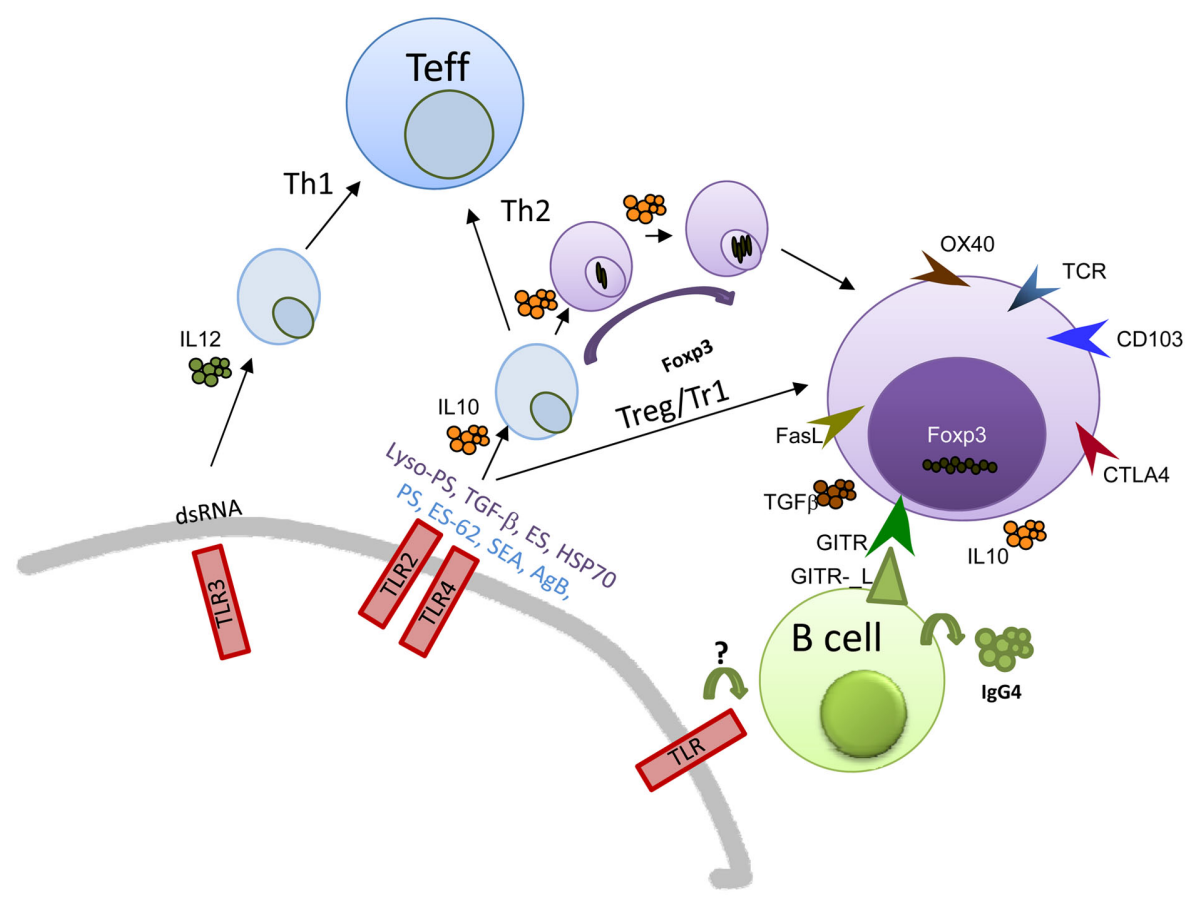

FIGURE 1 | Schematic illustration of TLR-Treg-B cell interactions during helminth infections. Multiple products derived from various life-stages of helminth parasite have been shown to trigger innate pathways such as TLR or $\mathrm{CTL}$. The triggering of such responses promotes a specific Th milieu although many have been shown to encourage Th2 or regulatory phenotypes. Alternatively, they may modulate responses to other innate stimuli or bystander antigens. Several helminth antigens have been shown to use TLR2 or 4 and some have been described to induce Treg. The ensuing Treg population is distinguished by their display of distinct markers such as GITR and CTLA-4. IL-10-producing Treg have been shown to promote IgG4 production by $B$ cells and in vitro this was found to be dependent on IL-10, TGF- $\beta$, and GITR-GITR-L interaction. These non-inflammatory scenarios would be beneficial during helminth infections since they would control excessive immune responses. 
GITR (Taylor et al., 2007). CTLA-4 is thought to aid the suppressive capacity of Treg by down-modulating CD80/86 expression on DCs to prevent antigen reactive naive $\mathrm{T}$ cells from being activated (Onishi et al., 2008).

\section{Treg AND B CELLS IN HELMINTH INFECTION}

One of the most well-characterized immune cell interplays has been elucidated in individuals infected with filariasis. As mentioned above, many infected patients have an asymptomatic condition which is characterized by elevated levels of Treg, IL-10, and filarial-specific IgG4 (Satoguina et al., 2002; Adjobimey and Hoerauf, 2010). IgG4 is the protective non-complement binding IgG subclass. The advantages of such B cell responses is apparent in patients suffering from allergy or helminth infections where high IgE responses need to be counter-regulated in order to avoid excessive immunopathology. Further in vitro studies were able to decipher that IL-10-producing $\mathrm{T}$ cells or Treg could induce IgG4 from B cells in an IL-10/TGF- $\beta$ dependent manner (Mahanty et al., 1996; Doetze et al., 2000; Satoguina et al., 2002, 2008; Adjobimey and Hoerauf, 2010). Such interactions were further shown to be mediated through cell contact and GITR-GITR-L interactions but interestingly not CTLA-4 (Satoguina et al., 2008). However, there is a small population of

\section{REFERENCES}

Adjobimey, T., and Hoerauf, A. (2010). Induction of immunoglobulin G4 in human filariasis: an indicator of immunoregulation. Ann. Trop. Med. Parasitol. 104, 455-464.

Aksoy, E., Zouain, C. S., Vanhoutte, F., Fontaine, J., Pavelka, N., Thieblemont, N., Willems, F., Ricciardi-Castagnoli, P., Goldman, M., Capron, M., Ryffel, B, and Trottein, F. (2005). Double-stranded RNAs from the helminth parasite Schistosoma activate TLR3 in dendritic cells. J. Biol. Chem. 280, 277-283.

Allen, J. E., and Maizels, R. M. (2011). Diversity and dialogue in immunity to helminths. Nat. Rev. Immunol. 11, 375-388.

Amu, S., Saunders, S. P., Kronenberg, M., Mangan, N. E., Atzberger, A., and Fallon, P. G. (2010). Regulatory B cells prevent and reverse allergic airway inflammation via FoxP3-positive $\mathrm{T}$ regulatory cells in a murine model. J. Allergy Clin. Immunol. 125, 1114-1124.e8.

Anthony, R. M., Rutitzky, L. I., Urban, J. F. Jr., Stadecker, M. J., and Gause, W. C. (2007). Protective immune mechanisms in helminth infection. Nat. Rev. Immunol. 7, 975-987.

Asahi, H., and Stadecker, M. J. (2003). Analysis of egg antigens inducing hepatic lesions in schistosome infection. Parasitol. Int. 52, 361-367.

Blackwell, N. M., and Else, K. J. (2001). B cells and antibodies are required for resistance to the parasitic gastrointestinal nematode Trichuris muris. Infect. Immun. 69, 3860-3868.

Blankenhaus, B., Klemm, U., Eschbach, M. L., Sparwasser, T., Huehn, J., Kuhl, A. A., Loddenkemper, C., Jacobs, T., and Breloer, M. (2011). Strongyloides ratti infection induces expansion of Foxp3+ regulatory $\mathrm{T}$ cells that interfere with immune response and parasite clearance in $\mathrm{BALB} / \mathrm{c}$ mice. J. Immunol. 186, 4295-4305.

Brattig, N. W., Bazzocchi, C., Kirschning, C. J., Reiling, N., Buttner, D. W., Ceciliani, F., Geisinger, F., Hochrein, H., Ernst, M., Wagner, H., Bandi, C., and Hoerauf, A. (2004). The major surface protein of Wolbachia endosymbionts in filarial nematodes elicits immune responses through TLR2 and TLR4. J. Immunol. 173, 437-445.

Conroy, H., Marshall, N. A., and Mills, K. H. (2008). TLR ligand suppression or enhancement of Treg cells? A double-edged sword in immunity to tumours. Oncogene 27, 168-180.

Correale, J., and Farez, M. (2009). Helminth antigens modulate immune responses in cells from multiple sclerosis patients through TLR2-dependent mechanisms. J. Immunol. 183, 5999-6012.

Correale, J., Farez, M., and Razzitte, G. (2008). Helminth infections associated with multiple sclerosis induce regulatory B cells. Ann. Neurol. 64, 187-199.

infected individuals that develop deliberating pathological symptoms and in contrast to hypo-responsive people, have elevated levels of IgE and IL-4 (Adjobimey and Hoerauf, 2010). Why and how these patients develop such polar responses remains unresolved. A possible hypothesis could be that during the development of worm-friendly environments, individuals suffer secondary infections, redirecting $B$ cell responses through alternative TLR-mediated actions and driving non-protective effector $\mathrm{T}$ cell repertoires.

As with every aspect of immunology, immune responses to any infection are never black and white. In vitro and in vivo experiments have both advantages and disadvantages but extrapolating those findings to "real-life" situations have to be viewed with caution. We are often extremely naive in how other aspects, such as our commensal flora or elements within the environment can sway our reactions. Within this review we have described multiple helminth-derived products that elicit both communal and unique host responses. Some of these mechanisms are TLR dependent either at the innate or adaptive side and such immunomodulation appears to benefit the worm in its long term relationship with the host but also the host from developing allergies or autoimmunity. Deciphering those molecules will hopefully provide new strategies in combating such diseases.

D’Elia, R., Behnke, J. M., Bradley, J. E., and Else, K. J. (2009). Regulatory T cells: a role in the control of helminth-driven intestinal pathology and worm survival. J. Immunol. $182,2340-2348$.

Doetze, A., Satoguina, J., Burchard, G., Rau, T., Loliger, C., Fleischer, B., and Hoerauf, A. (2000). Antigenspecific cellular hyporesponsiveness in a chronic human helminth infection is mediated by $T(h) 3 / T(r) 1-$ type cytokines IL-10 and transforming growth factor-beta but not by a $\mathrm{T}(\mathrm{h}) 1$ to $\mathrm{T}(\mathrm{h}) 2$ shift. Int. Immunol. 12, 623-630.

Everts, B., Smits, H. H., Hokke, C. H., and Yazdanbakhsh, M. (2010). Helminths and dendritic cells: sensing and regulating via pattern recognition receptors, Th2 and Treg responses. Eur. J. Immunol. 40, 1525-1537.

Fillatreau, S., Gray, D., and Anderton, S. M. (2008). Not always the bad guys: $B$ cells as regulators of autoimmune pathology. Nat. Rev. Immunol. 8, 391-397.

Gillan, V., and Devaney, E. (2005). Regulatory $\mathrm{T}$ cells modulate Th2 responses induced by Brugia pahangi third-stage larvae. Infect. Immun. 73, 4034-4042.

Goodridge, H. S., Marshall, F. A., Else, K. J., Houston, K. M., Egan, C., Al-Riyami, L., Liew, F. Y., Harnett, W., and Harnett, M. M. (2005). Immunomodulation via novel use of TLR4 by the filarial nematode phosphorylcholinecontaining secreted product, ES-62. J. Immunol. 174 284-293.

Goodridge, H. S., McGuiness, S., Houston, K. M., Egan, C. A., Al-Riyami, L., Alcocer, M. J., Harnett, M. M., and Harnett, W. (2007). Phosphorylcholine mimics the effects of ES-62 on macrophages and dendritic cells. Parasite Immunol. 29, 127-137.

Grainger, J. R., Smith, K. A., Hewitson, J. P., McSorley, H. J., Harcus, Y., Filbey, K. J., Finney, C. A., Greenwood, E. J., Knox, D. P., Wilson, M. S., Belkaid, Y., Rudensky, A. Y., and Maizels, R. M. (2010). Helminth secretions induce de novo $\mathrm{T}$ cell Foxp3 expression and regulatory function through the TGF-beta pathway. J. Exp. Med. 207, 2331-2341.

Haczku, A., Takeda, K., Hamelmann, E., Loader, J., Joetham, A., Redai, I., Irvin, C. G., Lee, J. J., Kikutani, H., Conrad, D., and Gelfand, E. W. (2000). CD23 exhibits negative regulatory effects on allergic sensitization and airway hyperresponsiveness. Am. J. Respir. Crit. Care Med. 161, 952-960.

Hall, J. A., Bouladoux, N., Sun, C. M., Wohlfert, E. A., Blank, R. B., Zhu, Q., Grigg, M. E., Berzofsky, J. A., and Belkaid, Y. (2008). Commensal DNA limits regulatory $\mathrm{T}$ cell conversion and is a natural adjuvant of intestinal immune responses. Immunity 29, 637-649. 
Harris, N., and Gause, W. C. (2010). To $\mathrm{B}$ or not to B: B cells and the Th2type immune response to helminths. Trends Immunol. 32, 80-88.

Hernandez, H. J., Wang, Y., and Stadecker, M. J. (1997). In infection with Schistosoma mansoni, B cells are required for $\mathrm{T}$ helper type 2 cell responses but not for granuloma formation. J. Immunol. 158, 4832-4837.

Hesse, M., Piccirillo, C. A., Belkaid, Y., Prufer, J., Mentink-Kane, M., Leusink, M., Cheever, A. W., Shevach, E. M., and Wynn, T. A. (2004). The pathogenesis of schistosomiasis is controlled by cooperating IL-10producing innate effector and regulatory $\mathrm{T}$ cells. J. Immunol. 172, 3157-3166.

Hoffmann, K. F., Cheever, A. W., and Wynn, T. A. (2000). IL-10 and the dangers of immune polarization: excessive type 1 and type 2 cytokine responses induce distinct forms of lethal immunopathology in murine schistosomiasis. J. Immunol. 164, 6406-6416.

Hori, S. (2010). Developmental plasticity of Foxp3+ regulatory T cells. Curr. Opin. Immunol. 22, 575-582.

Hotez, P. J., Brindley, P. J., Bethony, J. M., King, C. H., Pearce, E. J., and Jacobson, J. (2008). Helminth infections: the great neglected tropical diseases. J. Clin. Invest. 118, 1311-1321.

Hussaarts, L., van der Vlugt, L. E., Yazdanbakhsh, M., and Smits, H. H. (2011). Regulatory B-cell induction by helminths: implications for allergic disease. J. Allergy Clin. Immunol. 128, 733-739.

Kamradt, T. (2005). Can infections prevent or cure allergy and autoimmunity? Discov. Med. 5, 283-287.

Kane, C. M., Cervi, L., Sun, J., McKee, A. S., Masek, K. S., Shapira, S., Hunter, C. A., and Pearce, E. J. (2004). Helminth antigens modulate TLRinitiated dendritic cell activation. J. Immunol. 173, 7454-7461.

Korten, S., Badusche, OM., Buttner, D. W., Hoerauf, A., Brattig, N., and Fleischer, B. (2008). Natural death of adult Onchocerca volvulus and filaricidal effects of doxycycline induce local FOXP3+/CD4+ regulatory $\mathrm{T}$ cells and granzyme expression. Microbes Infect. 10, 313-324.

Kubo, T., Hatton, R. D., Oliver, J., Liu, X., Elson, C. O., and Weaver, C. T. (2004). Regulatory $\mathrm{T}$ cell suppression and anergy are differentially regulated by proinflammatory cytokines produced by TLRactivated dendritic cells. J. Immunol. 173, 7249-7258.
Layland, L. E., Mages, J., Loddenkemper, C., Hoerauf, A., Wagner, H., Lang, R., and da Costa, C. U. (2010). Pronounced phenotype in activated regulatory $\mathrm{T}$ cells during a chronic helminth infection. J. Immunol. 184 713-724.

Layland, L. E., Rad, R., Wagner, H., and da Costa, C. U. (2007). Immunopathology in schistosomiasis is controlled by antigen-specific regulatory $\mathrm{T}$ cells primed in the presence of TLR2. Eur. J. Immunol. 37, 2174-2184.

Linton, P. J., Bautista, B., Biederman, E., Bradley, E. S., Harbertson, J., Kondrack, R. M., Padrick, R. C., and Bradley, L. M. (2003). Costimulation via OX40L expressed by $\mathrm{B}$ cells is sufficient to determine the extent of primary CD4 cell expansion and Th2 cytokine secretion in vivo. J. Exp. Med. 197, 875-883.

Liu, Q., Kreider, T., Bowdridge, S., Liu, Z., Song, Y., Gaydo, A. G., Urban, J. F. Jr., and Gause, W. C. (2010). B cells have distinct roles in host protection against different nematode parasites. J. Immunol. 184, 5213-5223.

Lundy, S. K., and Boros, D. L. (2002). Fas ligand-expressing B-1a lymphocytes mediate CD4(+)-T-cell apoptosis during schistosomal infection: induction by interleukin 4 (IL4) and IL-10. Infect. Immun. 70, 812-819.

Mahanty, S., Mollis, S. N., Ravichandran, M., Abrams, J. S., Kumaraswami, V., Jayaraman, K., Ottesen, E. A., and Nutman, T. B. (1996). High levels of spontaneous and parasite antigen-driven interleukin-10 production are associated with antigen-specific hyporesponsiveness in human lymphatic filariasis. J. Infect. Dis. 173, 769-773.

Maizels, R. M., Balic, A., GomezEscobar, N., Nair, M., Taylor, M. D., and Allen, J. E. (2004). Helminth parasites - masters of regulation. Immunol. Rev. 201, 89-116.

Maizels, R. M., Pearce, E. J., Artis, D., Yazdanbakhsh, M., and Wynn, T. A. (2009). Regulation of pathogenesis and immunity in helminth infections. J. Exp. Med. 206, 2059-2066.

Maizels, R. M., and Yazdanbakhsh, M. (2003). Immune regulation by helminth parasites: cellular and molecular mechanisms. Nat. Rev. Immunol. 3, 733-744.

Mangan, N. E., Fallon, R. E., Smith, P., van Rooijen, N., McKenzie, A. N., and Fallon, P. G. (2004). Helminth infection protects mice from anaphylaxis via IL-10-producing B cells. J. Immunol. 173, 6346-6356.
McSorley, H. J., Harcus, Y. M., Murray, J., Taylor, M. D., and Maizels, R. M. (2008). Expansion of Foxp3+ regulatory $\mathrm{T}$ cells in mice infected with the filarial parasite Brugia malayi. J. Immunol. 181, 6456-6466.

Medzhitov, R., and Janeway, C. A. Jr. (1997). Innate immunity: the virtues of a nonclonal system of recognition. Cell 91, 295-298.

Meyer, S., van Liempt, E., Imberty, A. van Kooyk, Y., Geyer, H., Geyer, R., and van Die, I. (2005). DC-SIGN mediates binding of dendritic cells to authentic pseudo-LewisY glycolipids of Schistosoma mansoni cercariae, the first parasite-specific ligand of DC-SIGN. J. Biol. Chem. 280, 37349-37359.

Mills, K. H. (2008). TLR9 turns the tide on Treg cells. Immunity 29, 518-520.

Mitre, E., Chien, D., and Nutman, T. B. (2008). CD4(+) (and not $\mathrm{CD} 25+) \mathrm{T}$ cells are the predominant interleukin-10-producing cells in the circulation of filariainfected patients. J. Infect. Dis. 197, 94-101.

Moreau, E., and Chauvin, A. (2010). Immunity against helminths: interactions with the host and the intercurrent infections. J. Biomed. Biotechnol. 2010, 428593.

Moulin, V., Andris, F., Thielemans, K., Maliszewski, C., Urbain, J., and Moser, M. (2000). B lymphocytes regulate dendritic cell (DC) function in vivo: increased interleukin 12 production by DCs from B celldeficient mice results in T helper cell type 1 deviation. J. Exp. Med. 192, 475-482.

Okano, M., Satoskar, A. R., Nishizaki, K., Abe, M., and Harn, D. A. Jr. (1999). Induction of Th2 responses and IgE is largely due to carbohydrates functioning as adjuvants on Schistosoma mansoni egg antigens. J. Immunol. 163, 6712-6717.

Okano, M., Satoskar, A. R., Nishizaki, K., and Harn, D. A. Jr. (2001). Lacto-N-fucopentaose III found on Schistosoma mansoni egg antigens functions as adjuvant for proteins by inducing Th2-type response. $J$. Immunol. 167, 442-450.

Onguru, D., Liang, Y., Griffith, Q., Nikolajczyk, B., Mwinzi, P., and GanleyLeal, L. (2011). Human schistosomiasis is associated with endotoxemia and Toll-like receptor 2- and 4-bearing B cells. Am. J. Trop. Med. Hyg. 84, 321-324.

Onishi, Y., Fehervari, Z., Yamaguchi, T., and Sakaguchi, S. (2008). Foxp3+ natural regulatory $\mathrm{T}$ cells preferentially form aggregates on dendritic cells in vitro and actively inhibit their maturation. Proc. Natl. Acad. Sci. U.S.A. 105, 10113-10118.

Othman, A. A., El-Shourbagy, S. H., and Soliman, R. H. (2011). Kinetics of Foxp3-expressing regulatory cells in experimental Toxocara canis infection. Exp. Parasitol. 127, 454-459.

Pasare, C., and Medzhitov, R. (2005). Control of B-cell responses by Tolllike receptors. Nature 438, 364-368.

Pennock, J. L., and Grencis, R. K. (2006). The mast cell and gut nematodes: damage and defence. Chem. Immunol. Allergy 90, 128-140.

Perona-Wright, G., Jenkins, S. J., Crawford, A., Gray, D., Pearce, E. J., and MacDonald, A. S. (2006). Distinct sources and targets of IL-10 during dendritic cell-driven Th1 and Th2 responses in vivo. Eur. J. Immunol. 36, 2367-2375.

Ritter, M., Gross, O., Kays, S., Ruland, J., Nimmerjahn, F., Saijo, S., Tschopp, J., Layland, L. E., and Prazeres da Costa, C. (2010). Schistosoma mansoni triggers Dectin-2, which activates the Nlrp3 inflammasome and alters adaptive immune responses. Proc. Natl. Acad. Sci. U.S.A. 107, 20459-20464.

Rudensky, A. Y. (2011). Regulatory T cells and Foxp3. Immunol. Rev. 241, 260-268.

Rutitzky, L. I., and Stadecker, M. J. (2011). Exacerbated egg-induced immunopathology in murine Schistosoma mansoni infection is primarily mediated by IL-17 and restrained by IFN-gamma. Eur. J. Immunol. 41, 2677-2687.

Rzepecka, J., Rausch, S., Klotz, C., Schnoller, C., Kornprobst, T., Hagen, J., Ignatius, R., Lucius, R., and Hartmann, S. (2009). Calreticulin from the intestinal nematode Heligmosomoides polygyrus is a Th2skewing protein and interacts with murine scavenger receptor-A. Mol. Immunol. 46, 1109-1119.

Satoguina, J., Mempel, M., Larbi, J., Badusche, M., Loliger, C., Adjei, O., Gachelin, G., Fleischer, B., and Hoerauf, A. (2002). Antigen-specific T regulatory-1 cells are associated with immunosuppression in a chronic helminth infection (onchocerciasis). Microbes Infect. 4, 1291-1300.

Satoguina, J. S., Adjobimey, T., Arndts, K., Hoch, J., Oldenburg, J., Layland, L. E., and Hoerauf, A. (2008). $\operatorname{Tr} 1$ and naturally occurring regulatory $\mathrm{T}$ cells induce $\operatorname{IgG} 4$ in $\mathrm{B}$ cells through GITR/GITR-L interaction, IL-10 and TGF-beta. Eur. J. Immunol. 38, 3101-3113.

Schabussova, I., Amer, H., van Die, I., Kosma, P., and Maizels, R. M. (2007). 
O-methylated glycans from Toxocara are specific targets for antibody binding in human and animal infections. Int. J. Parasitol. 37, 97-109.

Schenten, D., and Medzhitov, R. (2011). The control of adaptive immune responses by the innate immune system. Adv. Immunol. 109, 87-124.

Smits, H. H., Everts, B., Hartgers, F. C., and Yazdanbakhsh, M. (2010). Chronic helminth infections protect against allergic diseases by active regulatory processes. Curr. Allergy Asthma Rep. 10, 3-12.

Tawill, S., Le Goff, L., Ali, F., Blaxter, M., and Allen, J. E. (2004). Both free-living and parasitic nematodes induce a characteristic Th2 response that is dependent on the presence of intact glycans. Infect. Immun. 72, 398-407.

Taylor, M. D., Harris, A., Babayan, S. A., Bain, O., Culshaw, A., Allen, J. E., and Maizels, R. M. (2007). CTLA4 and $\mathrm{CD} 4+\mathrm{CD} 25+$ regulatory $\mathrm{T}$ cells inhibit protective immunity to filarial parasites in vivo. J. Immunol. 179, 4626-4634.

Taylor, M. D., van der Werf, N., Harris, A., Graham, A. L., Bain, O., Allen, J. E., and Maizels, R. M. (2009). Early recruitment of natural CD4+ Foxp3+ Treg cells by infective larvae determines the outcome of filarial infection. Eur. J. Immunol. 39, 192-206.

Taylor, M. J., Hoerauf, A., and Bockarie, M. (2010). Lymphatic filariasis and onchocerciasis. Lancet 376, 1175-1185.

van der Kleij, D., Latz, E., Brouwers, J. F., Kruize, Y. C., Schmitz, M., KurtJones, E. A., Espevik, T., de Jong, E. C., Kapsenberg, M. L., Golenbock, D. T., Tielens, A. G., and Yazdanbakhsh, M. (2002). A novel hostparasite lipid cross-talk. Schistosomal lyso-phosphatidylserine activates toll-like receptor 2 and affects immune polarization. J. Biol. Chem. 277, 48122-48129.

van Die, I., van Vliet, S. J., Nyame, A. K., Cummings, R. D., Bank, C. M., Appelmelk, B., Geijtenbeek, T. B., and van Kooyk, Y. (2003). The dendritic cell-specific C-type lectin DC-SIGN is a receptor for Schistosoma mansoni egg antigens and recognizes the glycan antigen Lewis $\mathrm{x}$. Glycobiology 13, 471-478.

van Liempt, E., van Vliet, S. J., Engering, A., Garcia Vallejo, J. J., Bank, C. M., Sanchez-Hernandez, M., van Kooyk, Y., and van Die, I. (2007). Schistosoma mansoni soluble egg antigens are internalized by human dendritic cells through multiple C-type lectins and suppress TLR-induced dendritic cell activation. Mol. Immunol. 44, 2605-2615.

van Riet, E., Everts, B., Retra, K., Phylipsen, M., van Hellemond, J. J., Tielens, A. G., van der Kleij, D., Hartgers, F. C., and Yazdanbakhsh, M. (2009). Combined TLR2 and TLR4 ligation in the context of bacterial or helminth extracts in human monocyte derived dendritic cells: molecular correlates for Th1/Th2 polarization. BMC Immunol. 10, 9. doi:10.1186/1471-2172-10-9

Venugopal, P. G., Nutman, T. B., and Semnani, R. T. (2009). Activation and regulation of toll-like receptors (TLRs) by helminth parasites. Immunol. Res. 43, 252-263.

Voehringer, D. (2009). The role of basophils in helminth infection. Trends Parasitol. 25, 551-556.

Voo, K. S., Wang, Y. H., Santori, F. R., Boggiano, C., Wang, Y. H. Arima, K., Bover, L., Hanabuchi, S., Khalili, J., Marinova, E., Zheng, B., Littman, D. R., and Liu, Y. J. (2009). Identification of IL-17producing FOXP3+ regulatory $\mathrm{T}$ cells in humans. Proc. Natl. Acad. Sci. U.S.A. 106, 4793-4798.

Whelan, M., Harnett, M. M., Houston, K. M., Patel, V., Harnett, W. and Rigley, K. P. (2000). A filarial nematode-secreted product signals dendritic cells to acquire a phenotype that drives development of Th2 cells. J. Immunol. 164, 6453-6460.

Wilson, M. S., Mentink-Kane, M. M. Pesce, J. T., Ramalingam, T. R., Thompson, R., and Wynn, T. A. (2007). Immunopathology of schistosomiasis. Immunol. Cell Biol. 85, 148-154.

Wilson, M. S., Taylor, M. D., O'Gorman, M. T., Balic, A., Barr, T. A., Filbey, K., Anderton, S. M., and Maizels, R. M. (2010). Helminthinduced CD19+CD23hi B cells modulate experimental allergic and autoimmune inflammation. Eur. J. Immunol. 40, 1682-1696.

Yanaba, K., Bouaziz, J. D., Matsushita, T., Tsubata, T., and Tedder, T. F. (2009). The development and function of regulatory $\mathrm{B}$ cells expressing IL-10 (B10 cells) requires antigen receptor diversity and TLR signals. J. Immunol. 182, 7459-7472.

Conflict of Interest Statement: The authors declare that the research was conducted in the absence of any commercial or financial relationships that could be construed as a potential conflict of interest.

Received: 08 November 2011; paper pending published: 28 December 2011; accepted: 13 January 2012; published online: 01 February 2012.

Citation: Ludwig-Portugall I and Layland LE (2012) TLRs, Treg, and B cells, an interplay of regulation during helminth infection. Front. Immun. 3:8. doi: 10.3389/fimmu.2012.00008

This article was submitted to Frontiers in B Cell Biology, a specialty of Frontiers in Immunology.

Copyright () 2012 Ludwig-Portugall and Layland. This is an open-access article distributed under the terms of the Creative Commons Attribution Non Commercial License, which permits noncommercial use, distribution, and reproduction in other forums, provided the original authors and source are credited. 